\title{
Barriers to uptake of prevention of mother-to-child transmission of HIV services among mothers of vertically infected HIV-seropositive infants in Makurdi, Nigeria
}

\author{
This article was published in the following Dove Press journal: \\ Patient Preference and Adherence \\ 27 January 2016 \\ Number of times this article has been viewed
}

\section{Emmanuel Ademola \\ Anígilájél \\ Bem Ruben Ageda ${ }^{2}$ \\ Nnamdi Okechukwu \\ Nweke' \\ 'Department of Paediatrics, ${ }^{2}$ Department of Obstetrics and Gynaecology, Federal Medical Centre, Makurdi, Nigeria}

\begin{abstract}
Background: Perinatal transmission of human immunodeficiency virus (HIV) continues in Nigeria because of the poor use of prevention of mother-to-child transmission of HIV (PMTCT) services. This study reports on the barriers preventing mothers of vertically infected HIV-seropositive infants to use the PMTCT services at the Federal Medical Centre, Makurdi, Nigeria.
\end{abstract}

Methods: This is a descriptive study conducted between January and April, 2014. A quantitative survey was applied to detect barriers along the PMTCT services cascade among 52 mothers of vertically infected HIV-seropositive infants. This includes 22 women who attended antenatal care at the Federal Medical Centre (designated as Group A mothers) and 30 women who did not receive any form of PMTCT service (Group B mothers). The study was supplemented with a focused group discussion involving 12 discussants from the two groups.

Results: In the quantitative assessment: among the Group A mothers, falling asleep was the most common reason $(n=22,100 \%)$ for missing therapeutic/prophylactic antiretroviral medicine; financial constraint $(\mathrm{n}=22,100 \%)$ was the most common reason for antenatal care visit defaults; and a lot of the mothers $(n=11,50.0 \%)$ did not give nevirapine to their newborns because they delivered at home. Among Group B mothers, unawareness of HIV-seropositive status was the most common reason $(n=28,93.3 \%)$ given for not accessing PMTCT services. In the qualitative study: noninvolvement of male partners, stigma and discrimination experienced by HIVseropositive mothers, financial constraints in couples, involvement of traditional birth attendants in antenatal care and delivery of HIV-infected women, unawareness of HIV-seropositive status by pregnant women, poor health system, and the lack of funding for PMTCT services at private and rural health facilities were the major barriers preventing the use of PMTCT services.

Conclusion: In order to reduce the missed opportunities for PMTCT interventions in Makurdi and by extension the Benue State it represents in Nigeria, strong political and financial commitments are needed to overcome the identified barriers.

Keywords: obstacles, PMTCT services, Makurdi, Nigeria

\section{Introduction}

Among the 20 Global Plan priority countries, Nigeria has shown a slow decline (8\%) of new human immunodeficiency virus (HIV) infections recorded in children between 2009 and 2012. ${ }^{1}$ Nigeria has the largest number of children acquiring the HIV infection, nearly 60,000 in 2012, a number that has remained largely unchanged since 2009 . $^{1}$ Furthermore, $80 \%$ of HIV-infected pregnant women did not receive antiretroviral (ARV) medicines for prevention of mother-to-child transmission of HIV (PMTCT) in 2012. ${ }^{1}$
Correspondence: Emmanuel Ademola Anígilájé

Department of Paediatrics, Faculty of Clinical Sciences, College of Health Sciences, University of Abuja, PMB II7, Abuja, Nigeria

Email demolaanigilaje@yahoo.co.uk 
Without urgent action in Nigeria, the global target of a $50 \%$ decline of new pediatric HIV infections, set for between 2009 and 2015, is unlikely to be reached. This gloomy picture exists despite the fact that PMTCT services started in Nigeria in 2001 and there were 1,320 health care facilities offering these services in 2012. ${ }^{2}$ The National Agency for the Control of AIDS in Nigeria had earlier identified the challenges facing PMTCT services to include the poor use of these facilities despite the availability and commodities available, among other reasons. ${ }^{2}$ In Benue State, where the study was done, there are currently 200 PMTCT sites spread across all of the 23 local government areas, ${ }^{3}$ with the Federal Medical Centre (FMC) providing a tertiary level of PMTCT interventions in Makurdi, the state capital. However, in 2013, we reported that the mother-to-child transmission (MTCT) rate of HIV was $34 \%$ among children whose mothers did not access, initiate, and sustain PMTCT interventions. ${ }^{4}$ The PMTCT has four basic components: 1) prevention of primary infection among women of reproductive age-group; 2) prevention of unintended pregnancies among HIV-positive women; 3) provision of specific interventions to reduce the risk of MTCT; and 4) provision of care, treatment, and support to HIV-infected women, their infants, and families. ${ }^{5}$ In Nigeria, like any other resource constrained country, each of these components is plagued with many challenges, which cumulatively reduces the efficacy of the PMTCT services. ${ }^{6}$

Several studies have described the barriers negating PMTCT services in Nigeria. ${ }^{6-12}$ Worthy of note is the one by Hembah-Hilekaan et $\mathrm{al}^{12}$ which described the knowledge, attitudes, and barriers toward PMTCT of HIV in Uyam, a rural district of Zaki-Biam of Benue State. Using a quantitative survey, the researchers targeted antenatal care (ANC) attendees in a primary health care facility in the semi-urban community. ${ }^{12}$ Their study reveals that a significant number of women did not have an HIV test during pregnancy because of inadequate voluntary counseling and testing centers. Issues of stigma, absence of family support, and poor attitudes of staff were identified as barriers militating against PMTCT efforts. ${ }^{12}$ However, it is also well known that factors that impact on the success of PMTCT intervention can vary in different settings even within the same region/state of the same country. ${ }^{13}$ The present study focuses on mothers of HIV-infected infants who missed the opportunities for the uptake (herein refers to as access, initiation, and adherence) of PMTCT services at the FMC, Makurdi, Benue State. This study applied both quantitative and qualitative surveys, thereby giving a better in-depth understanding of the reasons for the failure of uptake of PMTCT services in the resource limited setting. This study is also worthy of international audience because Benue State has the highest HIV prevalence rates, with $10 \%$ in 2005 , $10.6 \%$ in 2008, and $12.7 \%$ in 2010 among pregnant women in ANC in Nigeria ${ }^{14}$ and, therefore, the findings from this study and those of Hembah-Hilekaan et al ${ }^{12}$ may largely reflect the barriers militating against PMTCT services in a setting with a high burden of perinatal HIV infection. If Nigeria is to attain the United Nations Global Plan target of eliminating new HIV infections in children ${ }^{15,16}$ and the Millennium Development Goals four (child health), five (maternal health), and six (HIV/AIDS), ${ }^{17,18}$ the barriers militating against PMTCT services have to be clearly and concertedly elucidated, before adequate remedial measures can be applied.

\section{Materials and methods Study design}

A cross-sectional study that applied both quantitative and qualitative surveys to the HIV-infected mothers of vertically infected HIV-seropositive infants presenting at FMC, Makurdi was used.

\section{Study area}

A comprehensive pediatric care and ARV therapy package for HIV-infected children started in Benue State at the FMC, Makurdi, in May 2006. Since the inception of the program, enrollment has been highest in the first quarter of every year and this study therefore took place between January and April 2014 to take advantage of this knowledge. Tertiary level PMTCT services are being provided with a team of medical personnel from the obstetrics and gynecology and pediatric departments. Although FMC is located in Makurdi, the urban capital city of Benue State, it also serves clients from the surrounding rural communities of the state. The facility is supported by the AIDS Prevention Initiative in Nigeria (APIN)/the US President's Emergency Plan for AIDS Relief (PEPFAR) program (Harvard).

\section{Ethical consideration}

The study was approved by the Research and Ethics Committee of the FMC, Makurdi. The study's objectives were explained to the HIV-infected mothers whose infants were vertically infected with HIV and it was emphasized that the information obtained from the study would be treated with utmost confidentiality and that anyone was at liberty to decline participation. It was also emphasized that declination to participate will not affect the care and treatment of their HIV-infected infants. Consecutively consenting HIV-infected mothers then signed a written consent form for an immediate 
quantitative survey and for a future focused group discussion (FGD), which was scheduled to be held at the end of the study period. For the purpose of the study, traceable home addresses and mobile phone numbers were obtained from the consenting mothers.

\section{PMTCT services at FMC, Makurdi}

During the period of study, the PMTCT interventions at FMC, Makurdi, followed the 2010 World Health Organization (WHO) recommendation, Option B. ${ }^{18}$ During the first ANC visit, all pregnant women received HIV testing and counseling and those who were found to be infected with HIV were screened for the clinical and immunological eligibility for the commencement of ARV therapy. Mothers who were eligible (ie, CD4 count $\leq 350$ cell $/ \mathrm{mm}^{3}$ ) received a highly active antiretroviral therapy (HAART) regimen including zidovudine plus lamivudine (3TC) plus nevirapine (NVP) from the time of HIV diagnosis, and is to be continued for life. Mothers who were not qualified for HAART (ie, CD4 count $>350$ cell $/ \mathrm{mm}^{3}$ ) also received HAART from 14 weeks of gestation or at any time following diagnosis until 1 week after exposure to breast milk had ended. Infantile prophylaxes for the HIV-exposed babies included daily doses of NVP, which were commenced within the first 72 hours of life and given for the first 6 weeks of life regardless of infant feeding option. The CD4 counts and HIV-1 ribonucleic acid level were measured at scheduled visits during ANC. The scheduled ANC visits followed the traditional pattern: monthly till 28 weeks, twice-weekly till 36 weeks, and weekly till delivery. Pretrained nurses also provided the necessary information to enable mothers to make informed decisions on either breastfeeding or replacement feeding. Emphasis was placed on avoidance of mixed feeding. Following delivery, infants were seen consecutively by a team which includes nurses, doctors, and pharmacists every 2 weeks for the first 6 weeks, every month for the first 3 months, and every 3 months till the age of 18 months. Early infant diagnoses with the DNA/ PCR were routinely offered at the sixth week and at the third month of life and the HIV antibody test at the 18th month when infants were then discontinued from care once found to be HIV uninfected and in an optimal nutritional state. Infants found to be HIV-infected at any point in time were promptly commenced on HAART in accordance with the clinical- and age-dependent immunological criteria of WHO guidelines of 2006. ${ }^{19}$ FMC also carried out rapid HIV screening tests during outreaches to the surrounding villages and pregnant women who were found to be HIV-positive were promptly referred to FMC for the continuation of PMTCT intervention as outlined previously. Male partners of HIV-infected women were also encouraged to participate in PMTCT services through a letter of invitation via their wives.

\section{Study population and operational definitions}

Included in the study were consecutive and willing HIVinfected mothers of HIV-infected infants who were either FMC's ANC defaulters who had partial PMTCT interventions (herein referred to as Group A) or HIV-infected mothers who did not receive any form of PMTCT interventions during pregnancy and/or labor (Group B). For Group A mothers, $\mathrm{HIV}$ testing was done at the antenatal care (ANC), as required in our PMTCT programme. Unfortunately, these Group A mothers did not assess a full PMTCT intervention and were recruited into the study because they came to the Federal Medical Centre with their sick infants who were found to be HIV infected. Thus, the Group A mothers were ANC attendees who were expected to have a full PMTCT service package but did not have it for one reason or the other. This explains how Group B mothers were recruited. Majority of these mothers (28 out of 30 ) got to know about their HIV status following HIV diagnosis in their sick infants well after the opportunity for PMTCT has been missed. Two of the Group B mothers were aware of their HIV status, even before pregnancy but still did not assess PMTCT. In both groups, the women were recruited into the study after they had come to FMC, Makurdi, because of their sick infants who were screened for and found to be HIV-infected, with horizontal transmission of HIV ruled out in these infants. A full PMTCT intervention was strictly defined as a combination of the following: first, optimal adherence on ARV medicine by HIV-infected pregnant women for their own HIV disease or for the purpose of PMTCT interventions; second, HIVexposed babies' receipt of ARV prophylaxes as described previously and optimal ANC attendance as described subsequently. All the HIV-infected infants had been mixed fed at presentation at the FMC. Figure 1 illustrates the cascades that define Group A and B mothers. Excluded were HIVinfected women whose infants were infected horizontally via blood transfusion.

Suboptimal adherence was when a mother missed three doses in a twice-daily regimen within any 30 -day period from the commencement of the ARV. Adherence was assessed by self-report from the mothers.

An infant is said to have missed ARV prophylaxis if he/she did not receive NVP within the first 72 hours of life and/or NVP was not given for the first 6 weeks of life.

Any one instance where the mother missed the ANC is regarded as a suboptimal antenatal attendance. 


\section{Group A}

22 mothers attended ANC at FMC Makurdi

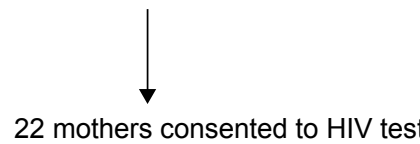

22 mothers consented to HIV test

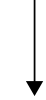

22 mothers received HIV test, 22 mothers received infant feeding counseling

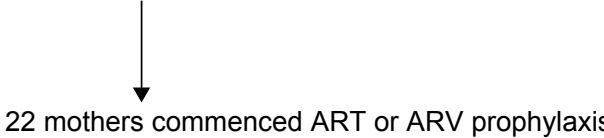

22 mothers commenced ART or ARV prophylaxis

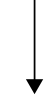

Optimal adherence on ART or ARV prophylaxis was not seen in all the 22 mothers

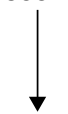

3 delivered at FMC, 11 delivered at home, 8 delivered at other health facilities

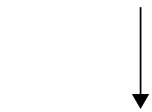

5 infants received infant ARV prophylaxis at FMC, other health facilities

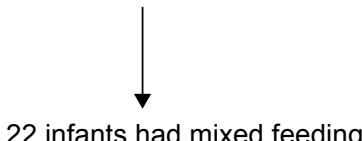

22 infants had mixed feeding

\section{Group B}

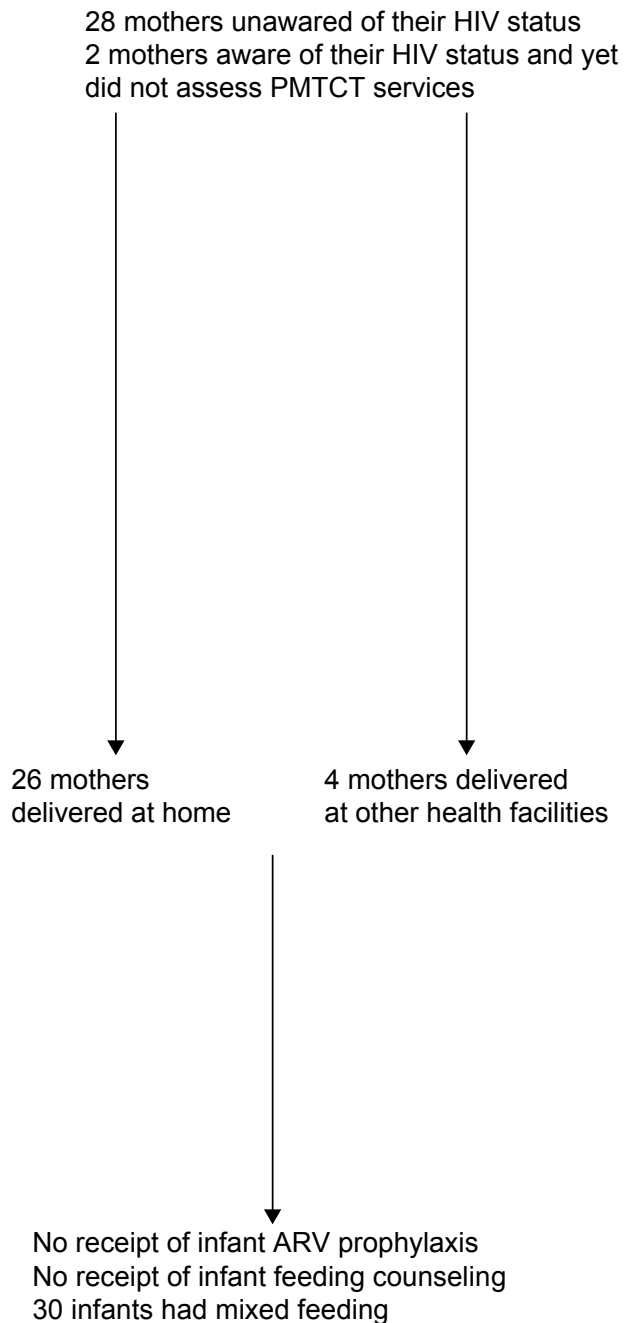

Figure I Cascades that define Group A and B mothers.

Abbreviations: ANC, antenatal care; FMC, Federal Medical Centre; ART, antiretroviral therapy; ARV, antiretroviral; PMTCT, prevention of mother to child transmission; HIV, human immunodeficiency virus.

\section{Data collection and management}

For quantitative analyses, a structured questionnaire was applied to the mothers at recruitment into the study to capture barriers of initiation and adherence to ARV medicine for the pregnant women and NVP for the HIV-exposed infants. Gourlay et $a{ }^{15}$ had earlier pointed that the receipt of ARV medicines by the pregnant women (either for their own HIV disease or as a prophylaxis for PMTCT) and their HIV-exposed infants is the most crucial component of PMTCT interventions; the questionnaire was thus structured to capture the potential barriers that impact on the uptake of ARV medicine by the women and their HIV-exposed infants at birth. The general format of the barriers to the uptake of ARV medicines as outlined by the Adult AIDS Clinical Trial Group adherence questionnaires by Barfod et $\mathrm{al}^{20}$ was modified to include the barriers that are peculiar to our setting. Also, the potential barriers to scheduled ANC attendances were also surveyed. In addition, questions were also asked about the reasons for the nonreceipt of PMTCT services for Group B mothers. By April 2014, qualitative data were also obtained using the FGD. The FGD involved 12 carefully selected mothers (who had earlier submitted a traceable home addresses and/or mobile phone numbers) who were adhering optimally to the clinic attendance of their HIV-infected infants and who were willing to participate in the discussion. The focused group discussants (FGds) included six members from both Groups A and B. The FGds were subsequently labeled 1-6 for Group A and 7-12 for Group B. Three doctors (a moderator, an audio recorder, and an observer) who had been previously trained for the study 
and who were not part of the PMTCT care providers at FMC, Makurdi, coordinated the FGD. These doctors were fluent in Tiv and Idoma indigenous languages. Their proficiency was verified through role-play and pretesting among another six mothers who were not part of the FGD. Audio-recorded FGD in the indigenous languages was later translated into English. Discussions took place in the waiting space of the clinic and lasted for 6 hours. A semi-structured format with open-ended questions was used. The questions covered the key findings from the quantitative study which then formed the themes for discussion (ie, reasons for suboptimal adherence on ARV medicine; reasons why mothers did not give NVP to their newborn infants; reasons for missing antenatal scheduled visit; reasons for infants' mixed feeding; and reasons for missing PMTCT services). In addition, the women's knowledge about HIV infection and the knowledge about the perceived risk of MTCT of HIV and suggestions on how to improve the PMTCT services were explored. For internal validity, data were collected until saturation point was reached. The key issues identified were also compared and contrasted among all the FGds.

\section{Statistical analysis}

For quantitative data, statistical analysis was done using SPSS version 16 (SPSS Inc., Chicago, IL, USA). Characteristics of the mothers were summarized using mean for continuous variables and proportions for categorical variables. Means between Group A and Group B were compared using the unpaired Student's $t$-test. Categorical values were compared using the chi-square and Fisher exact tests as appropriate. The responses from the quantitative survey were dichotomized into either "Yes" or "No" and the weight of the responses were noted by ranking. Further quantitative statistical analysis was not done as this would involve mothers who accessed PMTCT services and this was not the focus of this study. For the FGD, the quotations included in the text best represented the range of ideas voiced around the key themes. Anonymity of these quotes is maintained by identifying the discussants by their serial numbers and age.

\section{Results}

Out of a total of 67 mothers seen during the study period, 52 consented to participate in the study. Five infants were excluded because they had received blood transfusion and horizontal HIV transmission was possible.

Table 1 shows some sociodemographic characteristics of the 52 mothers. The 52 participants comprised of 22 Group A mothers (42.3\%) and 30 Group B mothers (57.7\%).
Comparison of the sociodemographic characteristics between the two groups revealed that significant differences exist only in terms of religion, educational attainment, and marital status. The trend was such that women in Group B tended to be of the Islamic faith $(P=0.044)$, more attained primary education $(P=0.000)$, and more were without any form of a partner $(P=0.010)$.

Table 2 reveals the reasons for suboptimal adherence on ARV medicine among the 22 Group A mothers and reasons why their infants missed the NVP prophylaxes.

The five most common reasons given by the Group A mothers for the suboptimal adherence on ARV in the descending order were "Fell asleep/slept through the dose time" ( $n=22,100 \%)$, "Ran out of pills" $(n=20,90.9 \%)$, "Simply forget" ( $\mathrm{n}=18,81.8 \%)$, "Did not want others to notice me while taking the ARV medication" ( $n=15,68.2 \%)$, and "Was away from home" ( $n=14,63.6 \%)$. Mothers did not miss ARV medicine for any of these reasons: "Used complementary medicine instead"; "Had problems taking pills at specified time (with meals, on empty stomach)"; "Had misunderstood the information about medications or dosing"; "Had a poor relationship with the physician"; and "Sold ARV". Other common reasons for suboptimal adherence on ARV medicines are summarized in Table 2.

The three most common reasons why Group A mothers did not give NVP to their newborn infants include: "Delivered baby at home" ( $\mathrm{n}=11,50.0 \%)$; "Delivery at other hospitals" $(\mathrm{n}=8,36.4 \%)$; and "Mother refused to give NVP for fear of someone finding/seeing the NVP" $(n=5,22.7 \%)$. The least common reasons why mothers did not give NVP included: "I forgot" ( $\mathrm{n}=2,9.1 \%)$ and "Baby did not tolerate NVP and I did not inform the health worker" $(n=2,9.1 \%)$.

Table 3 reveals the reasons for ever missing an antenatal scheduled visit among the 22 Group A mothers. The five most common reasons for missing ANC visits among the Group A mothers were "Lack of money to come for ANC" $(\mathrm{n}=22,100 \%)$; "Fear of someone finding/seeing me" $(\mathrm{n}=20$, 90.9\%); "Perceived poor staff attitude" ( $\mathrm{n}=19,86.4 \%)$; "Long distance to FMC" ( $\mathrm{n}=16,72.7 \%)$; and "Experienced long waiting times at ANC" $(\mathrm{n}=13,59.1 \%)$. The least common reason given for missing ANC by seven mothers (31.8\%) was "Experienced strain/violence following disclosure of HIV status to spouse".

Table 4 shows the reasons for missing PMTCT services among the 30 mothers in Group B. The most common reason for missing PMTCT services among 28 (93.3\%) women in Group B was "Unawareness about HIV infection status before pregnancy". This was followed by "Long distance of 
Table I Sociodemographic characteristics of the 52 mothers

\begin{tabular}{|c|c|c|c|c|}
\hline Variable & $\begin{array}{l}\text { Group A* (\%) } \\
\mathbf{N}=\mathbf{2 2}\end{array}$ & $\begin{array}{l}\text { Group B** (\%) } \\
\mathbf{N}=\mathbf{3 0}\end{array}$ & $\begin{array}{l}\text { Chi-square } \\
\text { (P-values) }\end{array}$ & $\begin{array}{l}\text { Student's t-test } \\
\text { unpaired ( } P \text {-values) }\end{array}$ \\
\hline \multicolumn{5}{|l|}{ Maternal age } \\
\hline Mean age, years & 30.68 & 27.77 & $4.7483(0.191)$ & $1.5860(0.1191)$ \\
\hline $15-24$ & $3(13.64 \%)$ & $9(30.0 \%)$ & & - \\
\hline $25-34$ & $12(54.55 \%)$ & 18 (60.0\%) & & - \\
\hline $35-39$ & $3(13.64 \%)$ & I (3.33\%) & & - \\
\hline$\geq 40$ & 4 (18.18\%) & 2 (6.67\%) & & - \\
\hline \multicolumn{5}{|l|}{ Religion } \\
\hline Christianity & 22 (100\%) & 25 (83.33\%) & $4.0567(0.044)$ & - \\
\hline Islam & 0 & $5(16.67 \%)$ & & - \\
\hline \multicolumn{5}{|l|}{ Ethnicity } \\
\hline Tiv & $19(86.36 \%)$ & 23 (76.67\%) & $0.7684(0.38 \mathrm{I})$ & - \\
\hline Idoma & $3(13.64 \%)$ & 7 (23.33\%) & & - \\
\hline \multicolumn{5}{|l|}{ Education level } \\
\hline None formal & 3 (13.64\%) & 14 (46.67\%) & I8.5425 (0.000) & - \\
\hline Primary & 7 (31.82\%) & $15(50.0 \%)$ & & - \\
\hline Secondary & $12(54.55 \%)$ & I (3.33\%) & & - \\
\hline \multicolumn{5}{|l|}{ Marital status } \\
\hline With a partner & I8 (8I.82\%) & 14 (46.67\%) & $6.626 \mathrm{I}(0.010)$ & - \\
\hline No partner & $4(18.18 \%)$ & $16(53.33 \%)$ & & - \\
\hline \multicolumn{5}{|c|}{ Income per month (minimum wage is 18,000 ) } \\
\hline Gets the minimum wage and above & $9(40.91 \%)$ & $5(16.67 \%)$ & $3.7913(0.052)$ & - \\
\hline Below the minimum wage & $13(59.09 \%)$ & $25(83.33 \%)$ & & - \\
\hline \multicolumn{5}{|l|}{ Parity } \\
\hline Mean & 3.22 & 1.8 & $0.9345(0.334)$ & $4.5421(0.000)$ \\
\hline Primiparous & $2(9.09 \%)$ & $17(56.67 \%)$ & & - \\
\hline More than one & $20(90.91 \%)$ & $13(43.33 \%)$ & & - \\
\hline \multicolumn{5}{|l|}{ Gestational age } \\
\hline Mean & 37.59 & 36.9 & $0.7684(0.38 \mathrm{I})$ & $2.0510(0.0455)$ \\
\hline Term & $19(86.36 \%)$ & $23(76.67 \%)$ & & - \\
\hline Preterm & $3(13.64 \%)$ & $7(23.33 \%)$ & & - \\
\hline \multicolumn{5}{|l|}{ Mode of delivery } \\
\hline Vaginal & 21 (95.45\%) & $24(80.0 \%)$ & $4.0655(0.131)$ & - \\
\hline Elective $\mathrm{C} / \mathrm{S}$ & I (4.55\%) & I (3.33\%) & & - \\
\hline Emergency $\mathrm{C} / \mathrm{S}$ & 0 & $5(16.67 \%)$ & & - \\
\hline
\end{tabular}

Notes: Time of booking/initiation of antenatal care for Group A; first trimester $=\mathrm{II}$, second trimester $=8$, and third trimester $=3$. $*$ These are mothers who had HIV testing done at the antenatal care (ANC) as required in our PMTCT programme, but unfortunately, these mothers did not assess a full PMTCT intervention and were recruited into the study because they came to the Federal Medical Centre with their sick infants who were found to be HIV infected. Thus, the Group A mothers were ANC attendees who were expected to have a full PMTCT service package but did not have it for one reason or the other. **These are mothers who got to know about their HIV status following HIV diagnosis in their sick infants, well after the opportunity for PMTCT has been missed. However, two of the Group B mothers were aware of their HIV status, even before pregnancy but still did not assess PMTCT.

Abbreviations: C/S, Cesarean section; PMTCT, prevention of mother-to-child transmission of HIV; HIV, human immunodeficiency virus.

HIV testing center to home/village" in 27 mothers (90\%); "Lack of confidentiality/privacy where HIV testing is done" in 26 women (86.7\%); and "Preferred home delivery with traditional birth attendant (TBA)" was also seen in 26 women. The least common response from six women $(20.0 \%)$ was "I did not have money to go to where HIV test is being done".

\section{Qualitative study}

Knowledge of HIV infection and the perceived risk of MTCT among Group A mothers

The six FGds (FGds-1-6) in Group A appeared to have a good understanding of HIV and its transmissibility from mother to the child during pregnancy, labor, delivery, and through breastfeeding. Also, all the FGds-1-6 agreed that they would have done everything possible to prevent missing their ARV medicines, but some circumstances were beyond their control. They were all aware that ANC attendance, delivery at the hospital, need to give NVP prophylaxis to infants at birth, and exclusive breastfeeding/replacement feeding were all important cascades of PMTCT services.

FGd-2, a 30-year-old, appeared to speak the mind of the other five mothers when she said:

I would have done everything possible to prevent my child from getting HIV from my system, but for circumstances 
Table 2 Reasons for suboptimal adherence on ARV medicine among the 22 Group A mothers and reasons why their infants missed the NVP prophylaxes

\begin{tabular}{|c|c|c|c|}
\hline Reasons & Yes, n* & Yes, \% & Rank \\
\hline Fell asleep/slept through the dose time & 22 & 100 & I \\
\hline Ran out of pills & 20 & 90.9 & 2 \\
\hline Simply forget & 18 & 81.8 & 3 \\
\hline Did not want others to notice me while taking the ARV & 15 & 68.2 & 4 \\
\hline \multicolumn{4}{|l|}{ medication } \\
\hline Was away from home & 14 & 63.6 & 5 \\
\hline Was busy with other things & 13 & 59.1 & 6 \\
\hline Had a change in daily routine & 12 & 54.5 & 7 \\
\hline Felt sick or ill & 11 & 50.0 & 8 \\
\hline Wanted a break from thinking about HIV & 9 & 40.9 & 9 \\
\hline Felt good & 8 & 36.4 & 10 \\
\hline Felt depressed/overwhelmed & 7 & 31.8 & 11 \\
\hline Drank alcohol & 5 & 22.7 & 12 \\
\hline Wanted to avoid side effects & 4 & 18.2 & 13 \\
\hline Thought medicine would work just as well & 4 & 18.2 & 13 \\
\hline Felt like drug was toxic/harmful & 4 & 18.2 & 13 \\
\hline Had difficulty taking pills because of taste or size & 3 & 13.6 & 14 \\
\hline Took drug/Indian hemp & 3 & 13.6 & 14 \\
\hline Had too many pills to take & 1 & 4.5 & 15 \\
\hline Lost/stolen ARV & I & 4.5 & 15 \\
\hline Used CAM instead & 0 & 0 & - \\
\hline Has problems taking pills at specified time & 0 & 0 & - \\
\hline \multicolumn{4}{|l|}{ (with meals, on empty stomach) } \\
\hline Had misunderstood the information about medications or dosing & 0 & 0 & - \\
\hline Had a poor relationship with your physician & 0 & 0 & - \\
\hline Sold ARV & 0 & 0 & - \\
\hline \multicolumn{4}{|l|}{ Reasons for missing infant prophylaxis } \\
\hline Home delivery & 11 & 50.0 & I \\
\hline Delivery at other hospital & 8 & 36.4 & 2 \\
\hline Mother refused to give NVP for fear of someone & 5 & 22.7 & 3 \\
\hline \multicolumn{4}{|l|}{ finding/seeing NVP } \\
\hline NVP syrup spilled & 4 & 18.2 & 4 \\
\hline NVP not available at the delivery room & 3 & 13.6 & 5 \\
\hline \multicolumn{4}{|l|}{ (deliveries happened over the weekend) } \\
\hline I forgot & 2 & 9.1 & 6 \\
\hline Baby did not tolerate NVP and I did not inform the health worker & 2 & 9.1 & 6 \\
\hline
\end{tabular}

Note: *Multiple responses possible.

Abbreviations: CAM, complementary and alternative medicine; ARV, antiretroviral medicine; NVP, nevirapine; HIV, human immunodeficiency virus.

beyond my control that made me register late at the ANC and which also prevented me from taking my ARV medicine regularly during pregnancy.

\section{Reasons why Group A mothers missed ARV medicine and why their newborns also missed the NVP prophylaxes}

Falling asleep through the scheduled dosing time was the most common reason given by all the FGds- $1-6$ for missing the ARV medicine. They noted that because of fatigue they tended to sleep through the evening doses of the ARV. They complained bitterly of inadequate support from their spouses who could have been helpful in this regard. They complained that their husbands tended to assume that "PMTCT is the business of the wives" and were unconcerned. This especially was so in HIVdiscordant couples. Even when the women tried to use a timed alarm clock, this often was unhelpful. They however put this "sleeping through" in proper context when they all agreed that it tended to occur more when they engaged in other activities such as going to the farm/market or coming for ANC.

FGd-2 said:

The stress of pregnancy on its own was tiresome; coupled with additional physical stress of going to the market or the farm, one tend to fall asleep earlier at night and forget to take the ARV medicine. Once I asked my husband to wake me up if I fall asleep before my 8 pm medicine; he shouted at me, called me a lazy woman and rather threatened to wake me up with a "Kobokobo" - a horsewhip. 
Table 3 Reasons for ever missing an antenatal scheduled visit among the 22 Group A mothers

\begin{tabular}{|c|c|c|c|}
\hline Reasons & Yes, n* $^{*}$ & Yes, \% & Rank \\
\hline Lack of money to come to ANC & 22 & 100 & I \\
\hline Fear of someone finding/seeing me & 20 & 90.9 & 2 \\
\hline Perceived poor staff attitude & 19 & 86.4 & 3 \\
\hline Long distance to FMC & 16 & 72.7 & 4 \\
\hline Experienced long waiting times at ANC & 13 & 59.1 & 5 \\
\hline $\begin{array}{l}\text { Lacked confidence in staff in keeping } \\
\text { confidentiality }\end{array}$ & 13 & 59.1 & 5 \\
\hline FMC staff went on an industrial strike & 11 & 50.0 & 6 \\
\hline $\begin{array}{l}\text { Unavailability of vehicles to convey } \\
\text { from the village }\end{array}$ & 10 & 45.5 & 7 \\
\hline Staff did not spend quality time with me & 8 & 36.4 & 8 \\
\hline $\begin{array}{l}\text { Experienced strain/violence following } \\
\text { disclosure of HIV status to spouse }\end{array}$ & 7 & 31.8 & 9 \\
\hline
\end{tabular}

Note: *Multiple responses possible.

Abbreviations: ANC, antenatal care; FMC, Federal Medical Centre; HIV, human immunodeficiency virus.

When asked why they ran out of ARV medicine, FGds1-6 all agreed that this often occurred during the industrial action embarked upon by health care workers at some time during the ANC. They did not bother to come for ANC for an ARV refill whenever there was an industrial action as they assumed that ARV would be unavailable. Also, they ran out of ARV medicine because of excessive vomiting of hyperemesis gravidarum. They were also afraid to come for a refill following wastages from vomiting for fear of being accused of selling the ARV. While none of the FGds-1-6 had ever sold ARV medicine, they, however, also agreed that some HIV-infected pregnant women do sell their ARV medicine to HIV-infected relations/people who because of stigmatization do not want to come to the ANC or ARV therapy clinic. On some occasions, the lack of money for transportation did not allow them to come for scheduled ANC visits for ARV refill.

FGd-5, a 31-year-old woman, said:

I was not sure that I will get ARV refill during industrial action and so I did not bother to come for ANC. I wasted some of my ARV medicine when I vomited persistently for 5 days during the first months of my pregnancy; but I was afraid to come for ARV refill before my scheduled appointment because the pharmacist may accuse me of selling my ARV medicine for profit. I also did not come at a point because my husband did not have transport money for my scheduled ANC clinic.

All the FGds-1-6 gave varying explanations on why they forgot to take their ARV medicine including: "it skipped my mind"; "when I woke up late and needed to quickly prepare
Table 4 Reasons for missing PMTCT services among the 30 mothers in Group B

\begin{tabular}{|c|c|c|c|}
\hline $\begin{array}{l}\text { Reasons for missing } \\
\text { PMTCT services }\end{array}$ & Yes, n* & Yes, \% & Rank \\
\hline $\begin{array}{l}\text { Unawareness about HIV infection status } \\
\text { before pregnancy }\end{array}$ & 28 & 93.3 & I \\
\hline $\begin{array}{l}\text { Long distance of HIV testing center to } \\
\text { home/village }\end{array}$ & 27 & 90.0 & 2 \\
\hline $\begin{array}{l}\text { Lack of confidentiality/privacy where HIV } \\
\text { testing is done at the village }\end{array}$ & 26 & 86.7 & 3 \\
\hline $\begin{array}{l}\text { Preferred home delivery with traditional } \\
\text { birth attendant (TBA) }\end{array}$ & 26 & 86.7 & 3 \\
\hline $\begin{array}{l}\text { Did not know where to do HIV testing } \\
\text { at FMC }\end{array}$ & 7 & 23.3 & 4 \\
\hline $\begin{array}{l}\text { Did not know that HIV testing is free at } \\
\text { FMC }\end{array}$ & 7 & 23.3 & 4 \\
\hline $\begin{array}{l}\text { I did not have money to go to where HIV } \\
\text { test is being done }\end{array}$ & 6 & 20 & 5 \\
\hline
\end{tabular}

Note: *Multiple responses possible.

Abbreviations: TBA, traditional birth attendant; PMTCT, prevention of motherto-child transmission of HIV; HIV, human immunodeficiency virus; FMC, Federal Medical Centre.

the family breakfast"; "when I had misunderstanding with my husband"; "when I am unhappy"; "during the early phase of initiation of ARV medicine"; and "when the ARV refill is about getting finished".

Fear of stigmatization and discrimination because of HIV serostatus was the main reason given by the FGds-1-6 for not wanting others to know that they were taking ARV medicine. This missing of ARV medicine occurred especially when couples were visited by the extended family members and the sleeping-room had to be shared with the pregnant women. They were afraid that the swallowing of ARV medicine would naturally generate curiosity from the visitors who may then want to know why they were regularly taking some medicines. They opined that once these visitors got to know about their HIV status, the risk of deliberate or inadvertent disclosure to other members of the family and the community is high. They also did not want to disclose their HIV status for the fear of making their relatives psychologically depressed or unhappy, as many people still believe that HIV infection is a death sentence. While trying to hide the ARV medicine from these visitors, they tended to forget to take it in the process. All of these reasons were well captured in the statement of FGd-5:

I hid my medication from visitors and forgot to take it in the process. I feared that if they should get to know about my HIV medicine, my family will soon become the subject of gossip among friends and other villagers. I will be discriminated against in the market and at social gathering. Some will not even want to sit close to me or shake hands with me in the 
church. This is even worse if it was my mother-in-law that was visiting. I would have hidden my ARV medicine, a day before her arrival. My husband feared that his mother would die quickly from depression and "too much of thinking" if she should get to know about the HIV infection.

The explanation given for missing ARV medicine when couples were away from home was that they forgot to take ARV medicine along with them on the journey. Intercommunal clashes and fire accidents at the farm were other disruptions cited for making some women to miss their ARV medicines. This occurred especially among women who have "routinized" their medication with the breakfast and dinner and any incident (such as those cited earlier) that disrupted the breakfast and/or the dinner times made them forgot to take the ARV medicines.

Most mothers also did not give NVP to their infants because they eventually delivered their babies at home under the supervision of the TBAs who virtually knew nothing about NVP prophylaxis. Mothers said they preferred home delivery to delivery at FMC, Makurdi, because of the less cost involved, convenience, and privacy home delivery provides. In addition, the TBAs are known for their tender loving care they provide to the mothers during the supervision of labor and delivery. They attested to the fact that although they received education about the need for NVP prophylaxis for their newborns during ANC, they did not disclose their HIV status to the TBAs because it made no difference in the care given by the TBAs. Even after deliveries by the TBAs, most women did not bring their infants back to FMC for NVP prophylaxis for fear of being chastised by the nurses for not delivering at FMC in the first place.

FGd-2 said:

It is the family tradition that we must delivered at home. In addition, home delivery is stress less and the TBA does not ask about one's HIV status. The TBA also showered us with love and we were confident in their proficiency. Unfortunately, provision of ARV medicine is not part of the routine of the TBA. I did not also know that I could still bring my baby for NVP prophylaxis at the FMC within the first 72 hours of life.

FGd-5 said:

I am aware that I could still bring my baby to FMC for NVP within the first 72 hours of life but I was afraid of the reaction of the nurses. They may openly abuse me for not keeping to their counsel and in the process, everybody around will get to know about my HIV status.
All the FGds-1-6 also agreed that it was the fear of stigmatization and discrimination that prevented mothers for asking someone else to give the NVP to their infants when they felt ill after delivery. Traditionally, mothers-in-law who came around to offer assistance after delivery and who were always in close contact with the newborns could not also give NVP to the babies because they would have to learn about the HIV status of the couple.

FGd-3, a 40-year-old woman, said:

During my last delivery, my mother-in-law came around and it was a battle giving my baby the NVP. I have to administer the NVP only when my mother-in-law was asleep. At times I gave the NVP in the afternoon and at some other times I gave it in the evening. For most days I missed giving the baby the NVP. It also affected my own ARV medicine doses.

Inadvertent delivery at some private hospitals where NVP was unavailable also happened when labor started at night and mothers had to be taken to the nearest hospital for deliveries. Some of these private hospitals did not offer PMTCT services and they would not request to know the mothers' HIV status. On rare occasions, infants also missed NVP because delivery took place over the weekend at FMC, whereupon NVP went out-of-stock at the labor room because of too many incidental deliveries.

\section{Reasons for missing scheduled ANC visits by Group A mothers}

All the FGds-1-6 agreed that lack of money to come to ANC was a major issue. Mothers had to choose between coming to ANC or engaging in other financially rewarding activities such as going to the market or the farm. The long distance to the FMC makes the journey tiresome and more costly. They would also not visit the nearest health center because of the fear that someone familiar may learn of their HIV status. They complained that their husbands also lacked money as salaries are being owed by their employers and/or lesser profit is being made from sale of farm produce. They also wished that the ANC visits are fewer in order to reduce the cost of transportation.

FGd-3 said:

Coming for $\mathrm{ANC}$ at times was a difficult decision especially when the ANC clinic falls on the market day. I lost money by not taking my produce to the market for sale and my husband could also not give me transport money.

The discussants again agreed that fear of stigmatization and discrimination when people learned of their HIV status 
caused them to deliberately default some ANC visits in order to reduce the possibility of someone they knew seeing them at the ANC. Some of the women also missed the ANC visits because of the unimpressive services they experienced at earlier ANC visits. They cited that some nurses making uncomplimentary and demeaning comments about their HIV status. They complained about the long wait time before they could be seen by a doctor. They felt that there was no confidentiality when they all have to assemble at the waiting space for PMTCT services and they were also unsure of the confidentiality by some clinic staff in keeping their HIV status private. They felt that they did not receive quality care as the time spent with the health workers was extremely short with little or no time for discussing the challenges they were having in pregnancy. For some who came from the villages, getting a vehicle to convey them to FMC was at times a problem; this is because there are very few vehicles that ply the bad roads from the villages and also because the volume of passengers is low and the drivers did not find it economically wise plying these roads. Furthermore, they also missed ANC visits during the industrial action embarked upon by the health workers because they thought that health workers would not be available to attend to them. A few mothers complained of a strained relationship with their husbands who accused them of deliberately dodging the farmwork to come to ANC. They then had to omit some antenatal visits for peace to reign in the family.

FGd-2 said:

I stopped coming when I was treated with disrespect and contempt by the ANC nurse. She made uncomplimentary comments about my HIV status. I felt if she could behave like this now, how will she behave when she has to take my delivery dealing with my blood.

FGd-4, a 30-year-old, said:

Coming to ANC is a day job. You cannot combine the ANC attendance with any other financially rewarding venture because of the long queue and the waiting times. Often, when it is eventually your turn, the nursing staff just rushed things over, you then begin to wonder whether it was worth the while coming to the $\mathrm{ANC}$ in the first place.

FGd-2 said:

We did not come for ANC at some points because of the industrial action embarked upon by the staff. It was later when we came back after the strike that we got to know strikes do not affect the PMTCT services. Again, once you missed the vehicle coming to Makurdi, one cannot come to ANC for that day. This was because of the few vehicles that ply the bad roads from the village and also because of the low volume of the passengers. This often gets worse whenever there is petrol scarcity or communal clashes as the road becomes dangerous to travel.

FGd-3 said:

I sneaked to attend the ANC because my HIV-negative husband was unsupportive. He felt that when people see me at the ANC they would readily conclude that he is also HIV-infected. Once, he beat me after I came back from the ANC and accused me of laziness and dodging to help on the farm.

\section{Reasons why infants of Group A mothers experienced mixed feeding}

Although all the mothers opted for replacement feeding, (following feeding counseling sessions about the needs for affordability, feasibility, acceptability, and sustainability of replacement feeding), they all engaged in mixed feeding. Unanimously, they attested that they could only do replacement feeding at home but whenever they were outside their homes, they had to breastfeed their infants, otherwise it may arise suspicion of their HIV-positive status by family, friends, and acquaintances.

FGd-4 captured it very well when she said:

I found myself able to give my baby the breast milk substitute only when I was at home and when my mother-in-law was not around. When I am in the church and I needed to feed my baby, I had to feed him with my breast milk in order not to arouse any suspicion from the congregation. You know, the awareness is there among the people that HIV-infected persons tended to give their babies formula feed instead of breast milk.

\section{Knowledge of HIV infection and the perceived risk of MTCT among Group B mothers}

The FGds-7-12 lacked adequate knowledge of HIV and its potential for MTCT. They were unaware of their HIV status or the risk of MTCT of HIV. At best, the women thought that MTCT of HIV was only possible during breastfeeding. They got to know about their HIV-positive status after delivery when their young infants started falling sick, which then made the doctor request for their HIV sero-status.

FGd-10, a 38-year-old woman, said and all others agreed: 
If I had known my HIV status and the risk of MTCT, I would have made myself available for PMTCT, for the sake of my innocent child.

\section{Barriers to uptake of PMTCT services by Group B mothers}

The most common barrier identified by the mothers for not taking PMTCT service was unawareness about their HIVseropositive status. They claimed that they did not do an HIV test because they thought that they could not afford the cost of HIV testing. They did not know that HIV testing has become an integral part of ANC that is offered free of charge. The TBAs who attended to their pregnancy, labor, and delivery also did not know about HIV and MTCT. Some who were aware of HIV testing during pregnancy did not do it because of fear of stigmatization and discrimination should they be positive as the HIV test could only be done at the village health facility where the confidentiality of the results cannot be guaranteed. They would have loved to do the HIV testing in another village but the cost of transportation prevented them from doing that. There existed a similar lack of confidentiality at the mobile HIV testing outreaches that visited the villages and this also did not encourage patronage. Even when HIV seropositivity was confirmed at these outreaches, referral to the FMC and other health facility where PMTCT is available was not often done. A lot of attrition took place and women found it difficult to trace the PMTCT center at the referred hospitals or at the FMC.

FGd-11, a 42-year-old, said:

I never thought about HIV infection. I never knew that MTCT is possible during pregnancy. I was hoping to do it after delivery as I only know that transmission is possible during breastfeeding. I was ignorant. Nobody cares to know about my HIV status.

FGd-8, a 19-year-old, said:

I did not know that it is possible to do HIV test at the ANC. If I had known I would have booked my pregnancy at the FMC. I thought one will do the HIV test somewhere and later take the result to ANC.

FGd-10 said:

In my village during HIV testing outreaches, people line up in a queue and you get to know who and who is positive. This information forms the village's gossip for a long time. I refused to do the HIV test because I do not want people to talk about me should I be HIV-positive. I also do not have the money for transportation to the next village to do the HIV test. Also, I believe strongly in the TBA to take my delivery. All my babies were born through their assistance. All they do was to bring the local concoction for me to drink at home. No injection. No blood collection. Once labor started, all I needed to do was just to send for the TBA who promptly attended to me at home. No need to pay for hospital bill. The TBA does not bother to know my HIV status.

FGd-12, a 37-year-old (one of the two women who was aware of HIV status but did not access PMTCT), said:

In my own case I summoned courage to do the HIV test during the community outreach. I was told I was positive and I was asked to come to FMC, Makurdi. When I got there I could not locate the people who came to our village for the HIV test. I was ashamed to ask people I met at the hospital where to go because they will know about my HIV status. I stopped going when I did not see these people at my third attempt.

\section{What could be done to improve the efficiency of the PMTCT services at FMC?}

The FGds emphasized the importance of reducing/eliminating the discrimination and stigmatization associated with HIV infection. They identified stigmatization to arise from the people's perception that HIV infection is a punishment for promiscuity and waywardness. They recognized discrimination to arise from the people's poor knowledge about the mode of HIV acquisition including the possibility of transmission via close physical contacts and sharing of eating utensils among others. They opined that if the challenges of stigmatization and discriminations of HIV are eliminated, people will be unrestrained to do HIV testing and more people would be willing to access the care and treatment for their own HIV disease or for the purpose of PMTCT. They suggested that the fundamental human rights of people living with HIV/ AIDS (PLWHA) in Benue State should be protected via enactment of laws at the Benue State Legislature and any person convicted of stigmatization and discrimination by competent court of jurisdiction should be punished by the State to serve as deterrents to others. The FGds agreed that more awareness has to be created starting from encouraging women of childbearing age to know their HIV status even before they get married or become pregnant. They suggested radio jingles since the listenership is broad and almost all households have a transistor radio which can be cheaply powered by batteries. 
They advised that information can be easily disseminated about HIV infection and its various routes of MTCT during pregnancy, delivery, and breastfeeding. They proposed that counseling and testing for HIV during community outreaches should be more confidential and the privacy therein improved upon. For women who were found to be HIV-positive, there must be adequate referral/linkage system to FMC, Makurdi, in a way that should prevent attrition/lost to follow-up. Involvement of male partners in ANC for PMTCT was also strongly advocated for. They opined that adherence on ARV medicine, NVP prophylaxis for infants, and ANC attendance would be greatly improved if husbands began to take ownership of the success of PMTCT outcomes. Mothers would be more likely to obtain the transportation fares for ANC attendance if husbands believe in the need for PMTCT services.

Mothers also suggested a possibility for reimbursement of transportation fees for ANC attendance. This form of reward is expected to positively reinforce ANC attendances. Other incentives such as provision of insecticide-treated nets, water purification solution (sodium hypochlorite), and the abolishment of all forms of out-of-pocket expenses will further enhance attendance at the ANC clinic. They suggested that the delivery of PMTCT services can be better if staff attitudes were improved as this would encourage more patronage. They opined that the recruitment of more staff would reduce the workload and thus guarantee a better client-staff interaction during ANC visits. They wanted improvement in the design of the waiting areas in a way that will guarantee privacy and confidentiality. The importance of informing mothers that PMCTC services are specialized care that continues regardless of any unforeseen industrial action by the clinical staff was also emphasized by the FGds.

\section{Discussion}

In 2001, Nigeria adopted the United Nations General Assembly Special Session goals of reducing the proportion of infants infected with HIV by $20 \%$ by 2005 and $50 \%$ by 2010 . However, with approximately 60,000 new pediatric HIV infections in 2012, it was obvious that these set goals were not achieved and Nigeria accounts for $30 \%$ of the global PMTCT gaps. ${ }^{21}$

The present study also reveals that MTCT of HIV in children still continues in an HIV endemic setting despite the availability of PMCTC services and commodities.

Maternal ARV therapy is a cornerstone in the cascade of PMTCT of HIV. ${ }^{15}$ The most common reason for suboptimal adherence on ARV medicine in this study was falling asleep/ sleeping through the dosing time of ARV. As revealed in the qualitative study, the physical exhaustion of pregnancy was the main reason why mothers fell asleep through the dosing time. Whereas, it may have been helpful if their spouses had been supportive; unfortunately, this was not the case. As noted by the FGds, the husbands of these women did not feel too concerned about PMTCT, which they regarded as a women issue. This often was seen among HIV-discordant couples. Traditionally, because of years of sex power imbalance, men have regarded issues related to pregnancy and childbirth as that of women's only and they do not see any need why this should be different for an HIV-infected pregnant woman. ${ }^{22}$ Ditekemena et $\mathrm{al}^{23}$ and $\mathrm{Koo}$ et $\mathrm{al}^{24}$ have reported that mothers who adhered to PMTCT programs have supportive husbands indicating that awareness and communication between couples about HIV infection are essential in the success of PMTCT interventions. In our program, efforts to involve male partners in PMTCT activities via special invitation letters through their wives were not successful. Although we were uncertain if such letters were delivered to the male partners, the fear of possible negative reactions of violence, stigma and discrimination, abandonments/divorce, or accusation of infidelity may have been responsible for the nondelivery of such letters. In actual fact, seven women reported strain/ violence following disclosure of HIV status to their spouses in this study. Medley et $\mathrm{al}^{25}$ had earlier reported the same negative reactions from South African men following disclosure of HIV-seropositive status by their wives in one study. Our program can, however, seek for further male participation in PMTCT by engaging in social marketing campaigns, workplace educational programs, reaching men where they work, and community outreaches and home visits as suggested by one report. ${ }^{26}$ Men can be engaged to remind their wives about the need to take ARV medicine since the majority of the women reported "Simply forget" as a cause of poor adherence on ARV medicine. Men can also be encouraged to assist their wives in the household chores in order to reduce the physical exhaustion women experienced following ANC visits and thus reduce the menace of "Sleeping through" the ARV dosing times. The consultation of couples who come for ANC can also be fast-tracked to serve as an incentive for men who have to leave their work for ANC attendance.

The qualitative survey revealed that HIV-infected women ran out of ARV medicine for reasons including not coming for refill during periods of industrial action by health care workers, wastages resulting from vomiting, inability to come for refill because of financial constrains, and unwholesome selling of ARV medicine by some women. The program is already taking measures to address some of these problems. 
Stigma and discrimination was another major barrier identified in this study. This barrier was pervasive as it affected the uptake of PMTCT services at all levels of the cascade. Stigma and discrimination was responsible for the following identified barriers: why mothers did not come for HIV testing; why mothers did not disclose HIV-seropositive status to their spouses; why mothers did not want to take ARV medicine in the presence of friends and family members either at home or when they travel; why mothers did not want to administer NVP to their infants in the presence of family members and friends; why mothers did not want to come for ANC visits; why mothers will breastfeed their babies outside their homes but will revert back to replacement feeding at home; and will also partly explain reason why mothers preferred home delivery supervised by TBAs.

Link and Phelan ${ }^{27}$ had defined stigma as a process that involves labeling the differences between those who are acceptable from those who are not, ascribing negative characteristics to these differences, and, finally, separating the acceptable from nonacceptable persons. Discrimination (or enacted stigma) has been described as the concrete acts that result from stigma and which result in unfair or biased treatment toward others based on external or behavioral characteristics of the person. ${ }^{28}$ During the qualitative study, all the four domains of stigma that have been described previousl ${ }^{28}$ were identified including: fear of casual transmission; values, shame, blame, and judgment; enacted stigma (discrimination); and disclosure. However, with proper education, the myths and misconceptions about HIV can be significantly reduced in our setting. The effects of felt and enacted stigma may be ameliorated by women's participation in self-help or psychosocial support groups. ${ }^{29}$ In Nigeria, there are no national laws in place specifically for the protection of PLWHA from discrimination based on their HIV status state. ${ }^{30}$ Although four states in Nigeria, including Enugu, Lagos, Cross River, and Nasarawa have state-level HIV/AIDS antidiscrimination laws, ${ }^{31}$ often the enforcement of these laws has been neglected and many PLWHA are not even aware of the existence of such laws. Regardless of these challenges, stigma and discrimination can be reduced in our setting if specific HIV/AIDS and sexual reproduction educational programs that emphasize the rights of PLWHA are promoted. These educational programs can be applied at the community and the state levels, using mass media campaigns, including television, radio, and newspapers. Also, PLWHA can be empowered in taking actions if their rights are violated. In this wise, nongovernmental organizations, faith-based organizations, significant others such as mothers-/fathers-in-law, community-based organizations, civil society organizations, and peer support group can all be mobilized toward achieving this common goal of reducing stigma and discriminations. The health care workers are also a strong agent of change in efforts at reducing stigma and discriminations.

Financial constraint is another major barrier of PMTCT uptake in this study. Women defaulted ANC attendance because of lack of money. Often, they have to choose between coming to $\mathrm{ANC}$ and pursuing other financially rewarding ventures. Also, the husbands of these women could not provide transport fees, and coming for ANC by these HIV-infected women is a common cause of family dispute. With the gradual withdrawal of financial assistance by the implementing partners, provision of the incentives suggested by the FGds (such as reimbursements of transport costs and abolition of users fees associated with institutional care and delivery services) to HIV-infected pregnant women for ANC attendance may become increasingly impossible. Therefore, the need for couples to be educated to see PMTCT services as a family priority and a positive way of life cannot be overemphasized. Families must be encouraged to give priorities to provision of transport fees for $\mathrm{ANC}$ attendance in the midst of competing financial obligations.

The roles of TBAs as a barrier in PMTCT activities also came to light in this study. The TBAs were engaged in taking deliveries of HIV women at home without any requisite knowledge of HIV and its potential for MTCT. In the qualitative study, mothers patronized TBAs because of their cheap services, the comfort they received from the TBAs, and because they did not feel any stigma or discrimination associated with HIV from the TBAs. Anyway, the TBAs are not even interested in knowing the HIV sero-status of the women. In Nigeria, in 2013, only $61 \%$ of pregnant women attended ANC, with $36 \%$ of women delivering at the health facilities, ${ }^{32}$ implying that the majority of Nigerian women still delivered at home under the supervision of the TBAs. As it stands, the involvement of the TBAs in the delivery of HIV-infected mothers cannot be overlooked, which then bears to mind the need for their training and retraining on PMTCT services. At the least, the TBAs can be trained on HIV testing using the rapid test kit and with a provision for a robust linkage/referral of HIV-seropositive women to FMC, Makurdi, or other health facilities that may offer PMTCT services.

The poor quality of PMTCT services experienced by the HIV women was another barrier identified in this study. Mothers complained of long waiting times, judgmental and 
poor staff attitude, lack of confidentiality at the waiting space, and the little time spent at the HIV counseling. While recruitment of more staff could reduce the burden of work load on health workers, the financial implication may not make this option an easy and immediate solution; therefore, efforts should be geared toward improving the efficiency of the existing workers via training and retraining on issues of PMTCT services. As earlier suggested by Barker et al, ${ }^{33}$ the health system efficiency can be optimized by close examination of the clinic flow, documentation of requirements, and other logistical improvements which can maximize the efficiency of services and decrease women's waiting times even with the existing staff strength. The use of peer or lay counselors, "expert" patients, and task shifting are other ways services can be dispersed across a wider number of personnel for a smoother service delivery. ${ }^{34}$

Unawareness of HIV-seropositive status was also a major barrier to initiating PMTCT intervention in this study. Some mothers did not see the need to come for PMTCT service because they did not know that they were HIV-infected in the first place. This revelation confirms the fact that the first two prongs (ie, prevention of primary infection among women of child-bearing age and prevention of unintended pregnancies among HIV-positive women) in the cascade of PMTCT service delivery are still very weak in our own setting. Since March 2014, the APIN PLUS/PEPFAR program at FMC, Makurdi, had stopped the mobile HIV testing outreaches to the villages because of the dwindling financial support; therefore, the Provider-Initiated HIV Testing and Counselling (with an opt-out option) must be optimized for all pregnant women coming for ANC and other women of child-bearing age coming to seek any form of health care at the FMC, Makurdi. Couple counseling and testing can also be adopted as this has been reported by Kakimoto et $\mathrm{al}^{35}$ and Msuya et $\mathrm{a}^{36}$ to be associated with increased acceptance of HIV testing by pregnant women in Cambodia and Tanzania, respectively. The offer of contraceptives to HIV-infected women during the postnatal care could be improved upon to give women the opportunity of choosing to get pregnant when they and their spouses are psychologically and financially ready for PMTCT service. Community mobilization via media campaigns can also draw the attention of the populace on the need to come for HIV testing and the potential danger of MTCT of HIV.

Noninvolvement of some private hospitals and some rural health facilities in the offering of PMTCT services was also seen in this study. This will explain the reason why some infants of mothers who inadvertently delivered at other hospitals could not be offered NVP prophylaxis. It will also explain the reason why some mothers have to travel long distances to come to FMC, Makurdi, for PMTCT services. The noninvolvement of the private health facilities in PMTCT services is more worrisome by the fact that approximately $38 \%$ of health facilities in Nigeria belong to the private sector. ${ }^{37}$ Although, the National Agency for the Controls of AIDS had advocated for decentralization of PMTCT services to include private and rural health facilities, Agboghoroma et $\mathrm{al}^{32}$ had earlier identified that poor buy-in at the state and local government levels, weak health systems, human resource limitations particularly in rural areas, and low utilization of maternal and child health care services are responsible for the slow process of decentralization. The issue of stigma and discrimination that discouraged women from patronizing health facilities nearer their homes as revealed in the qualitative study can also not be overlooked.

\section{Conclusion}

Noninvolvement of male partners, stigma and discrimination experienced by HIV-seropositive mothers, financial constraints of the couples, involvement of TBAs in ANC and delivery of HIV-infected women, unawareness of the HIV-seropositive status by pregnant women, poor health system, and the noninvolvement of private and rural health facilities in PMTCT services were the identified major barriers against effective PMTCT interventions in our own setting. Similar challenges have been identified by Hembah-Hilekaan et al $^{12}$ in Uyam, Benue State, Nigeria, and in other resource constrained sub-Saharan countries offering PMTCT services. ${ }^{38-40}$

The possible solutions proffered by the participants and the authors for the identified challenges of PMTCT services have been communicated to the Management Committee of the APIN/Harvard PEPFAR program of the FMC, Makurdi, and to the Executive Secretary of the Benue State AIDS Control Agency. For firm positive actions to be taken toward increased uptake of PMTCT interventions in our setting, the need for a strong political will in the midst of dwindling financial support from international partners cannot be overemphasized.

\section{Limitations of the study}

Although the study did not involve the health care workers of the PMTCT program to provide information about the challenges they faced in the provision of PMTCT services, the authors being major stakeholders in the program would 
readily identify the challenges to include: inadequate advertisement about the availability of PMTCT services at FMC, Makurdi; shortage of trained HIV counselors; shortage of trained midwives at deliveries of HIV-infected mothers; depletion of the few skilled personnel by in-service rotation to other departments; poor staff attitude; inadequate personal protective equipments during deliveries of HIV-infected mothers; and poor inventory taking that could explain running out of stock of NVP, especially for deliveries that happen over the weekend. The solutions proffered to these challenges have been included in the previously mentioned communication.

Also, like other qualitative studies, the sample size in this study was small and poorly probabilistic and, as such, generalization to other setting in Nigeria may not be plausible.

\section{Acknowledgments}

This work was funded in part by the US Department of Health and Human Services, Health Resources and Services Administration (U51HA02522), and the Centers for Disease Control and Prevention through APIN (PS001058). We also acknowledge Dr J Abah, the Principal Investigator of the program and Drs E Oko, JA Onoja, and KB Ahmed who served as research assistants during the FGD. We also appreciate all the women who participated in this study.

\section{Author contributions}

From May 2006 until March 2014, EAA was the pediatric coordinator of the AIDS Prevention Initiative in Nigeria (APIN)/Harvard PEPFAR (The USA President's Emergency Plan for AIDS Relief) program at the FMC, Makurdi. During this period, he was also a member of the Technical Committee of the program. He ensured that quality services are provided at the pediatric unit of the program. BRA was also the PMTCT coordinator during this period. Together, the duo supervised the robust linkages between the two units. All authors contributed toward data analysis, drafting and critically revising the paper and agree to be accountable for all aspects of the work.

\section{Disclosure}

The authors report no conflicts of interest in this work.

\section{References}

1. UNAIDS. 2013 progress report on the Global Plan towards the elimination of new HIV infections among children by 2015 and keeping their mothers alive; 2013. Available from: http://www.zero-hiv.org/ wp-content/uploads/2013/06/2013-progress-on-the-global-plan-en.pdf. Accessed December 15, 2013.
2. National Agency for the Control of AIDS (NACA). PMTCT demand creation for accelerated uptake of services. A national prevention of mother-to-child transmission (PMTCT) of HIV communication strategy, Nigeria, 2014. Available from: https://c-changeprogram.org/ sites/default/files/CChange_Nigeria_PMTCT_v9_web.pdf. Accessed January 3, 2016.

3. Benue State AIDS Control Agency (2013) Fact Sheet: Role out of PMTCT sites.

4. Anígilájé EA, Dabit OJ, Ageda B, Hwande S, Bitto TT. The prevalence and predictors of HIV infection among children of mothers who missed prevention of mother to child transmission of HIV interventions in Makurdi, Nigeria. J AIDS Clin Res. 2013;4:249.

5. World Health Organization. New guidance on prevention of mother-to-child transmission of HIV and infant feeding in the context of HIV; 2010. Available from: http://www.who.int/hiv/ pub/mtct/PMTCTfactsheet/en/index.html. Accessed December 15, 2013.

6. Ogunbosi BO, Oladokun RE, Awolude O, et al. Missed opportunities for prevention of mother-to-child transmission of HIV (PMTCT) in Ibadan, Southwest Nigeria. World J AIDS. 2014;4:356-364.

7. Balogun M, Odeyemi K. Knowledge and practice of prevention of mother-to-child transmission of HIV among traditional birth attendants in Lagos State, Nigeria. PAMJ. 2010;5:7.

8. Oladokun R, Awolude O, Brown B, et al. Service uptake and performance of the prevention of mother-to-child (PMTCT) programme in Ibadan, Nigeria. Afr J Med Sci. 2010;39(2):81-87.

9. Adeleke S, Mukhtar-Yola M, Gwarzo G. Awareness and knowledge of mother-to-child transmission of HIV among mothers attending the pediatric HIV clinic Kano, Nigeria. Ann Afr Med. 2009;8(4): $210-214$.

10. Moses A, Chama C, Udo S, Omotara B. Knowledge, attitudes and practise of antenatal attendees toward prevention of mother-tochild transmission (PMTCT) of HIV infection in a tertiary health facility, Northeast-Nigeria. East Afr J Public Health. 2009;6(2): 128-135.

11. Abiodun MO, Ijaiya MA, Aboyeji PA. Awareness and knowledge of mother-to-child transmission of HIV among pregnant women. $J$ Natl Med Assoc. 2007;99(7):758-763.

12. Hembah-Hilekaan SK, Swende TZ, Bitto TT. Knowledge attitudes and barriers towards prevention of mother-to-child transmission of HIV among women attending antenatal clinics in Uyam district of Zaki-Biam in Benue State, Nigeria: original research article. Afr J Reprod Health. 2012;16(3):27-34.

13. Adedimeji A, Abboud N, Merdekios B, Shiferaw M. A qualitative study of barriers to effectiveness of interventions to prevent motherto-child transmission of HIV in Arba Minch, Ethiopia. Inter J Pop Res. 2012;2012(532154):7. doi:10.1155/2012/532154.

14. Federal Ministry of Health, Abuja, Nigeria. ANC HIV Sentinel Survey, Federal Ministry of Health, Abuja, Nigeria; 2010. Available from: http://data.unaids.org/pub/Report/2010/nigeria_2010_country_progress_report_en.pdf. Accessed October 10, 2013.

15. Gourlay A, Birdthistle I, Mburu G, Iorpenda K, Wringe A. Barriers and facilitating factors to the uptake of antiretroviral drugs for prevention of mother-to-child transmission of HIV in sub-Saharan Africa: a systematic review. J Int AIDS Soc. 2013;16:18588.

16. Joint United Nations Programme on HIV/AIDS. Global Plan towards the elimination of new HIV infections among children by 2015 and keeping their mothers alive: 2011-2015. Geneva, Switzerland: United Nations; 2011.

17. United Nations. Millennium development goals; 2010. Available from: http://www.un.org/millenniumgoals/bkgd.shtml. Accessed December 5, 2012.

18. World Health Organisation. PMTCT Strategic Vision 2010-2015: Preventing Mother-to-Child Transmission of HIV to Reach the UNGASS and Millennium Development Goals. Geneva, Switzerland: World Health Organisation; 2010. Available from: http://www.who.int/hiv/ pub/mtct/strategic_vision.pdf. Accessed January 12, 2014. 
19. World Health Organization. Antiretroviral therapy of HIV infection in infants and children: towards universal access. Recommendation for a public health approach; 2006. Available from: http:/www.who.int/ hiv/pub/guidelines/WHOpaediatric.pdf. Accessed October 12, 2013.

20. Barfod TS, Sorensen HT, Nielson H, Rodkjaer L, Obels N. 'Simply forgot' is the most frequently stated reason for missed doses of HAART irrespective of degree of adherence. HIV Med. 2006;7:285-290.

21. UNAIDS. UBRAF 2012-2015 Country Case Study: Nigeria. Geneva: UNAIDS; 2011.

22. Gupta GR. How men's power over women fuels the HIV epidemic: It limits women's ability to control sexual interactions. BMJ. 2002; 324(7331): 183 .

23. Ditekemena J, Koole O, Engmann C, et al. Determinants of male involvement in maternal and child health services in sub-Saharan Africa: a review. Reprod Health. 2012;9(1):32.

24. Koo K, Makin JD, Forsyth BW. Barriers to male-partner participation in programs to prevent mother-to-child HIV transmission in South Africa. AIDS Educ Prev. 2013;25(1):14-24.

25. Medley A, Garcia-Moreno C, McGill S, Maman S. Rates, barriers and outcomes of HIV serostatus disclosure among women in developing countries: implications for prevention of mother-to-child transmission programmes. Bull World Health Organ. 2004;82(4):299-307.

26. Prevention of Mother-to-Child Transmission of HIV. Expert Panel Report and recommendations to the U.S. Congress and U.S. Global AIDS Coordinator. January 2010.

27. Link B, Phelan J. On stigma and its public health implications. Paper presented at: Stigma and Global Health: Developing a Research Agenda; 2001; Bethesda, MD. Washington: National Institutes of Health.

28. UNAIDS. HIV-related stigma, discrimination and human rights violations: case studies of successful programs. UNAIDS; 2005. Available from: http://whqlibdoc.who.int/unaids/2005/929173344X_eng.pdf. Accessed December 11, 2005.

29. Nguyen TA, Oosterhoff P, Ngoc YP, Wright P, Hardon A. Barriers to access prevention of mother-to-child transmission for HIV-positive women in a well-resourced setting in Vietnam. AIDS Res Ther. 2008; 17:5-7.

30. Global Network of People Living with HIV (GNP+). Global Criminalization Scan: Nigeria; September 3, 2012. Available from: http://www.gnpplus.net/criminalisation/country/nigeria. Accessed September 18, 2013.
31. Daily Trust. Nasarawa Gets Anti-HIV Stigma Law; October 10, 2012. Available from: http://www.dailytrust.com.ng/daily/old/index. php/news-news/747-nasarawa-gets-anti-hiv-stigma-law. Accessed October 12, 2013.

32. Agboghoroma CO, Sagay SA, Ikechebelu JI. Nigerian prevention of mother to child transmission of human immunodeficiency virus programme: the journey so far. J HIV Hum Reprod. 2013;1(1):1-7.

33. Barker P, McCannon CJ, Mehta N, et al. Strategies for the scale-up of antiretroviral therapy in South Africa through health system optimization. J Infect Dis. 2007;196 Suppl 3:S457-S463.

34. Zachariah R, Ford N, Philips M, et al. Task shifting in HIV/AIDS: opportunities, challenges and proposed actions for sub-Saharan Africa. Trans R Soc Trop Med Hyg. 2009;103:549-558.

35. Kakimoto K, Kanal K, Mukoyama Y, Chheng TV, Chou TL. Influence of the involvement of partners in the mother class with voluntary confidential counseling and testing acceptance for prevention of mother to child transmission of HIV programme (PMTCT programme) in Cambodia. AIDS Care. 2007;19:381-384.

36. Msuya SE, Mbizvo EM, Hussain A, Uriyo J, Sam NE, Stray-Pedersen B. Low male partner participation in antenatal HIV counseling and testing in northern Tanzania: implications for preventive programs. AIDS Care. 2008;20:700-709.

37. Federal Ministry of Health. A Directory of Health Facilities in Nigeria 2011. 786 Abuja, Nigeria: Federal Ministry of Health; 2011.

38. Theilgaard ZP, Katzenstein TL, Chiduo MG, et al. Addressing the fear and consequences of stigmatization - a necessary step towards making HAART accessible to women in Tanzania: a qualitative study. AIDS Res Ther. 2011;8(1):28.

39. Chinkonde JR, Sundby J, Martinson F. The prevention of mother-to-child HIV transmission programme in Lilongwe, Malawi: why do so many women drop out. Reprod Health Matters. 2009;17(33):143-151.

40. Manzi M, Zachariah R, Teck R, et al. High acceptability of voluntary counselling and HIV-testing but unacceptable loss to follow-up in a prevention of mother to child HIV transmission programme in rural Malawi: scaling up requires a different way of acting. Trop Med Int Health. 2005;10(12):1242-1250.
Patient Preference and Adherence

\section{Publish your work in this journal}

Patient Preference and Adherence is an international, peer-reviewed, open access journal that focuses on the growing importance of patient preference and adherence throughout the therapeutic continuum. Patient satisfaction, acceptability, quality of life, compliance, persistence and their role in developing new therapeutic modalities and compounds to optimize

\section{Dovepress}

clinical outcomes for existing disease states are major areas of interest for the journal. This journal has been accepted for indexing on PubMed Central. The manuscript management system is completely online and includes a very quick and fair peer-review system, which is all easy to use. Visit http://www. dovepress.com/testimonials.php to read real quotes from published authors. 